\title{
CULTURA DIGITAL E A FORMAÇÃO DO LEITOR LITERÁRIO NA BNCC: ELEMENTOS PARA REFLEXÃO
}

\author{
DIGITAL CULTURE AND THE TRAINING OF THE LITERARY READER AT BNCC: \\ ELEMENTS FOR REFLECTION
}

\section{CULTURA DIGITAL Y FORMACIÓN DEL LECTOR LITERARIO EN BNCC: ELEMENTOS DE REFLEXIÓN}

\author{
Analigia Miranda da Silva ${ }^{1}$ \\ Michelle Mittelstedt Devides ${ }^{2}$ \\ Bruna Janine Caballero Bezerra de Melo $^{3}$
}

\begin{abstract}
RESUMO
O presente artigo tem por objetivo compreender como a BNCC na área da Linguagem, Componente Curricular Língua Portuguesa (anos finais do Ensino Fundamental) - aborda a formação do leitor a partir da consideração da cultura digital e das Tecnologias Digitais da Informação e da Comunicação. Em consideração ao contexto contemporâneo, permeado pelas tecnologias digitais, a proposta da BNCC de Língua Portuguesa organiza os seguintes eixos de integração que envolvem as práticas de linguagem: leitura, produção de textos, leitura literária, oralidade e análise linguística/semiótica. Os eixos relacionamse com práticas de linguagem situadas e organizadas por campo de atuação. Delimitou-se para essa análise 0 eixo da leitura literária. A partir dessa definição na BNCC, considera-se a organização por campos de atuação, dentre eles escolhemos o campo artístico-literário. Os resultados do estudo indicam que as práticas contemporâneas de leitura e escrita são expressas por novos gêneros e produções textuais com características multissemióticas e multimidiáticas, 0 que revela a necessidade de 0 aluno compreender estas novas práticas de (multi) letramento (s), assim como seja capaz de ter uma postura ativa e construtiva, se constituindo em leitor e produtor de literatura de forma crítica e artística.
\end{abstract}

PALAVRAS-CHAVE: Formação do leitor. Tecnologias Digitais. BNCC.

\section{ABSTRACT}

This article aims to understand how the BNCC in the area of Language, Curriculum Component Portuguese Language (final years of Elementary School) - addresses the training of the reader from the consideration of digital culture and Digital Technologies of Information and Communication. Considering the contemporary context, permeated by digital technologies, the BNCC Portuguese Language proposal organizes the following integration axes that involve language practices: reading, text production, literary reading, orality and linguistic/semiotic analysis. The axes relate to language practices situated and organized by field of action. For this analysis, the axis of literary reading was delimited. From this definition in the BNCC, the organization by fields of action is considered, among them we chose the artistic-literary field. The study results indicate that contemporary reading and writing practices are expressed by new genres and textual productions with multisemiotic and multimedia characteristics, which reveals the need for the student to understand these new (multi) literacy(s) practices, as well as be able to have an active and constructive posture, becoming a reader and producer of literature in a critical and artistic way.

KEYWORDS: Reader formation. Digital Technologies. BNCC.

\section{RESUMEN}

Este artículo tiene como objetivo comprender cómo el BNCC en el área de Lengua, Componente Curricular Lengua Portuguesa (últimos años de Educación Primaria) - aborda la formación del lector desde la consideración de la cultura digital y las Tecnologías Digitales de Información y Comunicación. Considerando el contexto contemporáneo, permeado por las tecnologías digitales, la propuesta de

1 UENP/CJ. E-mail: analigiamiranda@gmail.com

2 UENP/CJ. E-mail: michelle.devides@pdl.ifmt.edu.br

3 UENP/CJ. E-mail: brunajaninecaballero@gmail.com

Revista de Ciências Humanas, Frederico Westphalen - RS, v. 22, n.2, p. 69-82, maio/ago. 2021. 
Lengua Portuguesa de BNCC organiza los siguientes ejes de integración que involucran prácticas lingüísticas: lectura, producción de textos, lectura literaria, oralidad y análisis lingüístico/semiótico. Los ejes se refieren a prácticas lingüísticas situadas y organizadas por campos de acción. Para este análisis se delimitó el eje de la lectura literaria. A partir de esta definición en el BNCC se considera la organización por campos de acción, entre ellos se eligió el campo artístico-literario. Los resultados del estudio indican que las prácticas de lectura y escritura contemporáneas se expresan en nuevos géneros y producciones textuales con características multisemióticas y multimedia, lo que revela la necesidad de que el alumno comprenda estas nuevas (multi) prácticas de alfabetización, así como ser capaz de comprender. Tener una postura activa y constructiva, convirtiéndose en lector y productor de literatura de manera crítica y artística.

PALABRAS CLAVE: Formación del lector. Tecnologías digitales. BNCC.

\section{INTRODUÇÃO}

'A palavra feita de luz mais que de vento' é um dos versos da canção 'Uma palavra', composta por Chico Buarque (1989). Podemos associá-lo ao ensaio de Antonio Candido (2011), 'O direito à literatura', tanto pela confirmação sobre a importância da literatura na experiência de vida de todas as pessoas quanto pela posição política e social que devemos assumir ao reconhecer e lutar por esse direito.

Imersos em um mundo extremamente tecnológico que possibilita circunstâncias efêmeras na contemporaneidade, é preciso reconhecer alguns caminhos necessários e fundamentais os quais permitem a efetiva mudança individual e social. Um dos caminhos é a arte, especialmente, a literatura. Antonio Candido (2011, p. 177), afirma que "[...] assim como não é possível haver equilíbrio psíquico sem o sonho durante o sono, talvez não haja equilíbrio social sem a literatura". Construímos nossas experiências a partir daquilo que vivenciamos e daquilo que sonhamos. Por vezes, permitimos o entrelaçamento para construir caminhos, realizar escolhas, perceber a realidade.

Para Culler (1999, p. 47), "A literatura é o ruído da cultura assim como sua informação. É uma força entrópica assim como um capital cultural. É uma escrita que exige uma leitura e envolve os leitores nos problemas de sentido". Então, acreditamos que a literatura permite explorar o mundo, olhar com outros olhos, conhecer outros lugares, reagir de diversas maneiras, sendo um caminho necessário para despertar no homem outras formas de conhecimento. Além disso, ao participar tão intensamente da vida humana e transgredir as estruturas socialmente definidas, em busca de um conhecimento inédito ou peculiar para cada sujeito, a literatura se ajusta aos modelos e rompe paradigmas quando não se adequa mais a nenhum modelo existente. 
Nesse sentido, é necessário aliar a tecnologia às experiências de leitura literária na formação de jovens leitores, cabendo à escola o desenvolvimento de ações que permitam associar diferentes habilidades de leitura.

Na contemporaneidade, as tecnologias digitais têm permitido o rompimento definitivo de tempo e espaço, possibilitando o acesso global e imediato ao conhecimento produzido pela humanidade. A digitalização da informação descortina novas possibilidades de construção e comunicação dos saberes. Esse novo cenário revela a necessidade de se (re) pensar o papel que a escola deve desempenhar na formação dos alunos no atual contexto sociocultural. Com as mudanças nas formas de se relacionar, comunicar e conhecer, propiciadas pelo avanço dos recursos tecnológicos que permeiam e transformam a sociedade atual e o consequente redimensionado de aspectos socioculturais, nos deparamos com a iminência da revisão de currículos e práticas educacionais, decorrente do surgimento de novas necessidades formativas.

Uma das dimensões formativas que se alinha à contemporaneidade se dá no campo da Língua Portuguesa e suas literaturas em associação com as Tecnologias Digitais de Informação e Comunicação (TDIC's). Tal dimensão encontra expressão em um importante documento normativo que tem como objetivo central definir as aprendizagens essenciais e ser referência para a constituição dos currículos de todas as escolas brasileiras: a Base Nacional Comum Curricular (BNCC) de 2018. O documento expressa com ênfase a relevância das tecnologias digitais nas questões da sociabilidade e da formação humana, especialmente na dimensão da formação do leitor. Nesse sentido, esse estudo tem por objetivo compreender como a BNCC na área de Linguagem, - Componente Curricular Língua Portuguesa (anos finais do Ensino Fundamental) - aborda a formação do leitor a partir da consideração da cultura digital e das Tecnologias Digitais da Informação e da Comunicação. Para atingir tal objetivo, apresentamos um breve itinerário sobre o papel desempenhado pela escola na formação do leitor; a influência da cultura digital sobre o leitor contemporâneo e, principalmente, como a BNCC entrelaça essas questões tendo em vista seu caráter orientador e normativo.

\section{O Papel da Escola na Formação do Leitor Literário}

A partir do século XVIII, as obras destinadas ao público infantil e juvenil começaram a aparecer no mercado de livros europeu. Segundo Lajolo e Zilberman (1985), como a industrialização foi o fenômeno que mais marcou este século, a representação ideológica de tal feito também ocorreu, ou seja, as artes como um todo representaram o processo de mudanças econômicas, políticas e sociais que correspondiam ao período. 
A criança, nesse contexto, começa a aparecer socialmente de forma significativa, dando a ideia de continuidade de um lar, fator muito importante para a manutenção de uma burguesia nascente. Sendo assim, esse público passa a receber um olhar diferenciado, iniciando uma jornada de produtos e serviços voltados à criança e ao jovem. Porém, é importante refletir que esse avanço correspondia à visão que o adulto tinha a respeito da criança, o que, muitas vezes, minimizava seu potencial e a diminuía diante de todas as suas capacidades, pois se constituía como um olhar unilateral.

A escola aparece como uma importante aliada da burguesia, visto que, enquanto instituição representava a sociedade ideologicamente. Em consequência, a escola adquire, a partir de então, uma centralidade formativa e social para as famílias e lares burgueses. $\mathrm{Na}$ instituição escolar, essa criança e esse jovem poderiam se preparar melhor e amadurecer para se adequar ao mundo de forma condizente ao que as famílias desejavam.

Desse modo, acompanhando a sociedade que se modernizava através da industrialização e tecnologia, a literatura assumiu um papel de mercadoria, juntamente ao avanço da tipografia e a produção de livros que se expandiu. Mas, é importante lembrar que, ao se pensar em literatura, pensamos na leitura, a qual estava diretamente associada à presença das crianças na escola, tornando o acesso à leitura dos livros e à literatura possível apenas para aqueles que frequentavam o ambiente escolar. Assim, a literatura infantil e juvenil participava cada vez mais da formação da sociedade contemporânea, ainda que restrita à burguesia.

Esse crescimento da presença da literatura também está atrelado à maior participação das crianças nas escolas, como já mencionado. Contudo, acabou efetivando uma posição da literatura submissa à educação, assumindo uma postura, muitas vezes, pedagógica, a fim de justificar sua utilidade.

Partindo disso, o mais importante é que, mesmo sendo vistas e tratadas como instrumento de leitura e escolarização, algumas obras infanto-juvenis sobreviveram, como os contos de fadas de Perrault e os clássicos de Robinson Crusoé, por exemplo. Já no século XIX, os contos dos irmãos Grimm foram exemplos de histórias muito lidas e que perduraram até hoje, reforçando que as narrativas fantásticas e de aventuras prevalecem no gosto do leitor infantil e juvenil, fator que evidencia a liberdade do imaginário das crianças e adolescentes. Portanto, a arte literária, mesmo em meio a tantas limitações causadas por vários fatores, mostra a sua capacidade de sobreviver, construindo um lugar próprio e autônomo.

No cenário brasileiro, quando a literatura infanto-juvenil começa a ganhar público e força, a Europa já apresenta um contexto forte e sólido. Mas, adequando-se à realidade local e com características próprias, a nossa literatura para jovens e crianças começa a ocupar o seu 
espaço, mesmo que tardiamente, "dentro desse panorama, mas respondendo a exigências locais, emerge a vertente brasileira do gênero, cuja história, particular e com elementos próprios, não desmente o roteiro geral". (LAJOLO; ZILBERMAN, 1985, p. 21).

As escritas poéticas para crianças e adolescentes sempre foram alvo de debates polêmicos no âmbito dos estudos literários. Nesse contexto, sabemos que a maioria das crianças e jovens adquirem sua formação literária no espaço escolar, onde, normalmente, ocorre 0 letramento literário, como pode ser visto no decorrer de nossa história. Mas, é justamente nesse aspecto que observamos as falhas, pois o letramento literário nas escolas brasileiras ainda é uma prática distante do ideal.

Partindo disso, discutir sobre a importância da literatura dentro dos modelos racionais, científicos e, muitas vezes, rígidos da escola é urgente e necessário, visto que somente através dessas reflexões poderemos mudar a realidade da presença da literatura na grande maioria das escolas brasileiras. A forma sistemática e rígida do pensamento científico presente no processo de escolarização, acaba descartando a subjetividade, as relações afetivas, os contextos emocionais que fazem parte da nossa existência enquanto seres humanos.

Como já dito anteriormente, sabe-se que a escola é o ambiente onde a maior parte das crianças e adolescentes iniciam seu contato com a leitura literária. Sendo assim, se a instituição escolar continua com uma grande demanda de textos com caráter pragmático e um reduzido contato com textos poéticos, o estímulo à leitura literária torna-se cada vez mais distante.

É importante pontuar que a literatura apresenta uma forma específica de organização da linguagem: o discurso poético. Através dessa linguagem, podemos representar aspectos subjetivos, psicológicos e emocionais, ambiguidades, contradições e o imaginário. Dessa maneira, reforça-se a importância do contato com esse tipo de linguagem para as crianças e adolescentes, os quais estão em sua fase mais livre do imaginário e formando sua estrutura emocional e psicológica. Logo, se privados dessa oportunidade, nossas crianças perdem 0 direito de conhecer, ler, usar, escrever e usufruir da literatura e todas as suas possibilidades.

Esse olhar diferenciado e diversificado que o discurso poético propõe, justifica a importância da leitura da literatura infantil e juvenil no espaço escolar. Assim, a literatura infantojuvenil deve ser vista como uma prática social de importância singular na formação do jovem leitor. Reforça-se, então, que a escola é um ambiente de extrema importância para estabelecer o contato da criança e do jovem com a leitura literária, bem como ajuda as práticas de leituras dos indivíduos a não se reduzirem apenas a textos pragmáticos.

Segundo Azevedo (2005), as produções da literatura infantil e juvenil possuem uma linguagem organizada de forma mais acessivel, resultando em uma maior identificação com 0 
público leitor. Normalmente, um dos recursos é a aproximação entre a linguagem verbal e nãoverbal na composição do livro para crianças e jovens.

Ressalta-se, mais uma vez, a importância da discussão sobre a presença efetiva da literatura nas escolas, solidificando o lugar legítimo das escritas poéticas e suprindo a necessidade do contato das pessoas com a literatura para que as práticas leitoras não se reduzam a, por exemplo, livros didáticos, bulas de remédios ou mensagens em redes sociais.

Assim, a literatura infanto-juvenil, enquanto produto cultural, situa-se como possibilidade artística independente e, também, como literatura de massa destinada ao consumo do público infantil. Cabe ao professor, ao invés de execrar alguns modelos ou superestimar os clássicos, observar todo o contexto do seu alunado para fazer escolhas de leituras que se adequem aos inúmeros aspectos representativos os quais farão da leitura um momento de lazer, aprendizado e reflexão.

Afinal, a literatura em si apresenta múltiplas funções. O discurso literário através de seu potencial simbólico e criativo não é minimizado quando utilizado para o ensino, sendo visto como fonte de construção do saber. Logo, ao invés de se pensar sobre a presença da literatura em sala de aula, deve-se pensar sobre como abordá-la em sala de aula, com o intuito de não diminuir o prazer da leitura do texto literário. A experiência de leitura para essas crianças e jovens deve ser, antes de tudo, prazerosa e compatível a todo o contexto em que esses alunos estão inseridos:

\footnotetext{
Sem nenhuma pretensão ao rigor de que pretendem revestir-se várias disciplinas que se ocupam da infância, a literatura trabalha em surdina. Enquanto formadora de imagens, a literatura mergulha no imaginário coletivo e simultaneamente o fecunda, construindo e desconstruindo perfis de crianças que parecem combinar bem com as imagens de infâncias formuladas e postas em circulação a partir de outras esferas, sejam estas científicas, políticas, econômicas ou artísticas. Em conjunto, artes e ciências vão favorecendo que a infância seja o que dizem que ela é [...] e, simultaneamente, vão se tornando o campo a partir do qual se negociam novos conceitos e novos modos de ser da infância. (LAJOLO; ZILBERMAN, 1997, p. 232).
}

Pensar na criança e no adolescente inseridos em um contexto escolar que ofereça a linguagem artística de forma humanizadora é imprescindível. Mas, infelizmente, sabemos que a realidade em sala de aula é bem diferente, já que a grande maioria das instituições escolares, sejam elas públicas ou privadas, não utilizam a literatura, por exemplo, como prioridade.

Pensando nas fases do contexto escolar, vê-se na Educação Infantil a presença da leitura e contação de histórias como fator primordial ao processo educativo. Porém, ao chegar no Ensino Fundamental (anos iniciais e finais), vê-se a utilização da leitura como suporte para 0 letramento linguístico. Nesse momento, 0 ato de ler e escrever passam a ser prioridade e a 
imaginação, o faz de conta, o processo de plurissignificação e o prazer de ler Literatura começam a ser reduzidos a meros fragmentos presentes em livros didáticos ou a adoção de livros paradidáticos que são, em sua maioria das vezes, lidos e trabalhados de forma superficial.

Já no Ensino Médio, temos o respaldo da obrigatoriedade documentada pelo Ministério da Educação na prática da disciplina de Literatura. Mas o problema surge com novo formato: a Literatura ao invés de ser lida, é tratada como um processo histórico, através de muitos períodos a serem estudados e muitos autores a serem lembrados. Mais uma vez temos uma distância criada entre o leitor e a obra.

\section{A Cultura Digital e a Formação do Leitor: a BNCC em questão}

A proposta de uma base curricular comum foi prevista na Constituição Federal de 1988, na Lei de Diretrizes e Bases da Educação (Lei n 9.394/1996), e no Plano Nacional de Educação (PNE), de 2014. Homologada no final de 2017, a BNCC se constitui como:

[...] um documento de caráter normativo que define o conjunto orgânico e progressivo de aprendizagens essenciais que todos os alunos devem desenvolver ao longo das etapas e modalidades da Educação Básica, de modo a que tenham assegurados seus direitos de aprendizagem e desenvolvimento, em conformidade com o que preceitua o Plano Nacional de Educação (PNE). Este documento normativo aplica-se exclusivamente à educação escolar, tal como a define $0 \S 1^{\circ}$ do Artigo $1^{\circ}$ da Lei de Diretrizes e Bases da Educação Nacional (LDB, Lei no 9.394/1996), e está orientado pelos princípios éticos, políticos e estéticos que visam à formação humana integral e à construção de uma sociedade justa, democrática e inclusiva. (BRASIL, 2018, p. 7).

$\mathrm{Na}$ Base Nacional Comum Curricular (BNCC), temos que o componente Língua Portuguesa compreende o aspecto da prática social. Segundo o documento é preciso:

[...] proporcionar aos estudantes experiências que contribuam para a ampliação dos letramentos, de forma a possibilitar a participação significativa e crítica nas diversas práticas sociais permeadas/constituídas pela oralidade, pela escrita e por outras linguagens. (BRASIL, 2018, p. 67-68).

Nesse sentido, enfatiza-se que o trabalho pedagógico com os diversos gêneros textuais deve não se pautar apenas na leitura e produção de texto, mas que se afine a um conhecimento de mundo.

É importante ressaltar que o escrito/impresso não é colocado em segundo plano pela BNCC. $O$ que se propõe é considerar os multiletramentos, dentre os quais, temos aqueles essencialmente digitais. Para se pensar os multiletramentos cabe fazer um apanhado histórico das tecnologias de informar e comunicar que, enquanto produtos da cognição humana, nos revelam contextos sócio-históricos, a dinâmica social e de produção de conhecimento de cada 
momento da humanidade. A oralidade, a escrita e a atual era das redes determinam, em suas diferentes fases, os modos como o homem constrói, aprende e transmite/compartilha saberes. Nesse sentido, os recursos tecnológicos alteram a nossa relação com 0 mundo quando influenciam dimensões relacionadas aos modos de produzir e comunicar informações.

$\mathrm{Na}$ oralidade, a informação linguística é atrelada ao homem e restrita ao tempo e ao espaço no qual está inserido. Nesse contexto, a possibilidade de disseminação e sistematização de saberes é rudimentar e localizada, pois o alcance social dos saberes produzidos ficava limitado à memória dos indivíduos e sua duração transitória, dadas as características desta fase.

A fase escrita, seguida pela informação tipográfica, amplificou a capacidade humana de produzir e comunicar saberes e contribuiu para a complexificação dos conhecimentos já que, nesse momento, era possível mantê-los disponíveis e preservados de forma definitiva para 0 outro. A possibilidade de expansão do espaço e tempo no qual o conhecimento circula determinou a objetivação e universalidade do conhecimento produzido também propiciado pela possibilidade de separação entre memória e sujeito, impossível na era da oralidade e, nesse contexto, "[...] a exigência de uma verdade universal, objetiva e crítica só pôde se impor numa ecologia cognitiva largamente estruturada pela escrita, ou, mais exatamente, pela escrita sobre um suporte estático". (LÉVY, 1996, p. 38).

Dessa forma, em um primeiro momento histórico, temos a informação linguística que é atrelada ao sujeito e tem por característica a impossibilidade de objetivá-la. Posteriormente, iniciamos o processo de objetivação da comunicação e da informação por meio de instrumentos, sendo inicialmente a informação escrita, seguida pela informação tipográfica e, atualmente, a informação digital. Segundo Coll e Monereo (2010, p. 17),

\footnotetext{
Entre todas as tecnologias criadas pelos seres humanos, aquelas relacionadas com a capacidade de representar e transmitir informação - ou seja, as tecnologias da informação e da comunicação - revestem-se de uma especial importância, porque afetam praticamente todos os âmbitos de atividades das pessoas, desde as formas e práticas de organização social até o modo de compreender o mundo, de organizar essa compreensão e de transmiti-la para outras pessoas. As TIC têm sido sempre, em suas diferentes fases de desenvolvimento, instrumentos para pensar, aprender, conhecer, representar e transmitir para outras pessoas e para outras gerações os conhecimentos adquiridos.
}

Assim, temos a redefinição dos novos ambientes on-line para além da organização e acesso de informações, além de serem dotados de potencialidades para se constituírem enquanto serem espaços didáticos mediadores de uma aprendizagem pautada em bases construtivas e colaborativas, tendo em vista o modo não hierárquico dos ambientes em rede e a possibilidade de uso enquanto instrumentos de metacognição. 
Considerando o contexto contemporâneo, permeado pelas tecnologias digitais, a proposta da BNCC de Língua Portuguesa organiza os seguintes eixos de integração que envolvem as práticas de linguagem: leitura, produção de textos, leitura literária, oralidade e análise linguística/semiótica. Os eixos relacionam-se com práticas de linguagem situadas e organizadas por campo de atuação. Delimita-se para essa análise o eixo da leitura, especificado da seguinte maneira na BNCC:

Leitura no contexto da BNCC é tomada em um sentido mais amplo, dizendo respeito não somente ao texto escrito, mas também a imagens estáticas (foto, pintura, desenho, esquema, gráfico, diagrama) ou em movimento (filmes, vídeos etc.) e ao som (música) que acompanha e cossignifca em muitos gêneros digitais. (BRASIL, 2018, p. 72).

A partir dessa definição na BNCC, considera-se a organização por campos de atuação, dentre eles delimitamos o campo artístico-literário, pois contempla "uma formação estética vinculada à experiência de leitura e escrita do texto literário e à compreensão e produção de textos artísticos multissemióticos". (BRASIL, 2018, p. 84).

A BNCC de Língua Portuguesa dos anos finais do Ensino Fundamental não aborda diretamente 0 ensino da literatura, no entanto, faz apontamentos sobre a formação do leitor por meio do campo artístico-literário de forma mais ampla. Contudo, aponta para a importância de reconhecer que a "cultura digital perpassa todos os campos, fazendo surgir ou modificando gêneros e práticas". (BRASIL, 2018, p. 85).

Além disso, deve-se considerar que para subsidiar esse processo de aproximação entre o leitor e o campo artístico-literário, a BNCC indica que diversas formas de manifestações possam ser experienciadas pelo leitor para que este desenvolva a fruição estética. A dimensão humanizadora, transformadora e mobilizadora deveria garantir "um leitor-fruidor, ou seja, de um sujeito que seja capaz de se implicar na leitura dos textos, de "desvendar" suas múltiplas camadas de sentido, de responder às suas demandas e de firmar pactos de leitura" (BRASIL, 2018, p. 138). Dessa forma, há um distanciamento da função utilitária da literatura e há a preocupação em desenvolver habilidades que ampliem o conhecimento literário dos leitores em formação, considerando alguns elementos como a polifonia, intertextualidade e diferentes mídias, por exemplo.

Para indicarmos as associações entre a cultura digital e as práticas de linguagem, retoma-se, primeiramente, 0 item 5 das Competências gerais de Língua Portuguesa da BNCC, 0 qual aponta que as tecnologias digitais estão diretamente relacionadas ao desenvolvimento de competências na área da Linguagem. Segundo o documento, o aluno deve: 
Compreender, utilizar e criar tecnologias digitais de informação e comunicação de forma crítica, significativa, reflexiva e ética nas diversas práticas sociais (incluindo as escolares) para se comunicar, acessar e disseminar informações, produzir conhecimentos, resolver problemas e exercer protagonismo e autoria na vida pessoal e coletiva. (BRASIL, 2018, p. 9).

Além disso, as competências específicas enfatizam duas questões importantes sobre a leitura literária e a dimensão da cultura digital,

\begin{abstract}
Envolver-se em práticas de leitura literária que possibilitem o desenvolvimento do senso estético para fruição, valorizando a literatura e outras manifestações artísticoculturais como formas de acesso às dimensões lúdicas, de imaginário e encantamento, reconhecendo o potencial transformador e humanizador da experiência com a literatura. Mobilizar práticas da cultura digital, diferentes linguagens, mídias e ferramentas digitais para expandir as formas de produzir sentidos (nos processos de compreensão e produção), aprender e refletir sobre 0 mundo e realizar diferentes projetos autorais. (BRASIL, 2018, p. 87).
\end{abstract}

Percebemos que o documento destaca que as mudanças promovidas pela cultura digital incidem em mudanças sociais, tendo o jovem como protagonista desse processo. Para além disso, ressalta como pontos negativos desse novo contexto, "imediatismo de respostas e a efemeridade das informações, privilegiando análises superficiais e o uso de imagens e formas de expressão mais sintéticas, diferentes dos modos de dizer e argumentar característicos da vida escolar". (BRASIL, 2018, p. 61).

A solução vislumbrada na BNCC para a formação desse novo leitor é que a escola estimule a reflexão crítica do estudante frente aos conteúdos das múltiplas ferramentas midiáticas. Para tanto, o campo da didática orienta que a escola incorpore em suas práticas as novas linguagens e seus respectivos modos de funcionamento, garantindo uma participação consciente e democrática na cultura digital. As potencialidades comunicativas do mundo digital são dadas como novos modos de aprender, integrar e compartilhar saberes entre professores e alunos. (BRASIL, 2018).

A partir de tais condenações, a BNCC expõe que "as práticas de linguagem contemporâneas não só envolvem novos gêneros e textos cada vez mais multissemióticos e multimidiáticos, como também novas formas de produzir, de configurar, de disponibilizar, de replicar e de interagir". (BRASIL, 2018, p. 68).

Sendo o objeto do nosso estudo alinhado ao Eixo Leitura, que é tomado na BNCC em sentido mais amplo, abrangendo imagens estáticas e em movimento em relação aos diversos gêneros digitais, apresentamos a seguir, duas práticas de uso e reflexão elencadas pela BNCC e estritamente relacionadas ao contexto digital: 
Refletir sobre as transformações ocorridas nos campos de atividades em função do desenvolvimento das tecnologias de comunicação e informação, do uso do hipertexto e da hipermídia e do surgimento da Web 2.0: novos gêneros do discurso e novas práticas de linguagem próprias da cultura digital, transmutação ou reelaboração dos gêneros em função das transformações pelas quais passam o texto (de formatação e em função da convergência de mídias e do funcionamento hipertextual), novas formas de interação e de compartilhamento de textos/ conteúdos/informações, reconfiguração do papel de leitor, que passa a ser também produtor, dentre outros, como forma de ampliar as possibilidades de participação na cultura digital e contemplar os novos e os multiletramentos.

Analisar as diferentes formas de manifestação da compreensão ativa (réplica ativa) dos textos que circulam nas redes sociais, blogs/microblog, sites e afins e os gêneros que conformam essas práticas de linguagem, como: comentário, carta de leitor, post em rede social, gif, meme, fanfic, vlogs variados, political remix, charge digital, paródias de diferentes tipos, vídeos-minuto, e-zine, fanzine, fanvídeo, vidding, gameplay, walkthrough, detonado, machinima, trailer honesto, playlists comentadas de diferentes tipos etc., de forma a ampliar a compreensão de textos que pertencem a esses gêneros e a possibilitar uma participação mais qualificada do ponto de vista ético, estético e político nas práticas de linguagem da cultura digital. (BRASIL, 2018, p. 72-73).

Observamos que a BNCC traz o conceito Web 2.0. As ferramentas da Web 2.0 permitem a produção e publicação em um ambiente social, sendo a utilização, seleção e controle das informações determinadas pelo usuário. Por suas possibilidades de interação, comunicação e produção permitem o surgimento de um novo paradigma que se relaciona a uma cultura da aprendizagem. A Web 2.0 possibilita a relação direta entre os sujeitos por meio de redes sociais com características interativas e colaborativas onde é possível sair da passividade para a produção ativa de informações. Compreendemos que a interatividade permitida pelas ferramentas da Web 2.0 associada à participação ativa dos usuários, resulta na inteligência coletiva que na perspectiva de Lévy (2007, p. 28) "[...] é distribuída por toda parte, incessantemente valorizada, coordenada em tempo real, que resulta em uma mobilização efetiva das competências".

Sobre esse contexto contemporâneo e a formação do leitor, Santaella (2013) em seu artigo 'Leitor prossumidor: desafios da ubiquidade para a educação' aponta para quatro tipos de leitores que 'navegam' pelo ciberespaço, sendo eles: contemplativo, movente, imersivo e ubíquo. Para a autora, o leitor contemplativo é aquele que se situa na idade pré-industrial, leitor do livro impresso e da imagem expositiva e fixa. O leitor movente advém da revolução industrial e do surgimento dos grandes centros urbanos, e, portanto, um leitor de um mundo dinâmico e dos sinais e linguagens características das metrópoles. 0 leitor imersivo é aquele que se relaciona ao contexto das tecnologias de informação e comunicação e traz em suas habilidades cognitivas elementos distintos dos leitores anteriores.

Já não temos uma linearidade na leitura, mas, "roteiros multilineares, multissequenciais e labirínticos que ele próprio ajuda a construir ao interagir com os nós que transitam entre textos, 
imagens, documentação, músicas, vídeo etc". (SANTAELLA, 2013, p. 27). Por fim, Santaella (2013) nos traz um novo perfil cognitivo do leitor: o ubíquo. Sobre esse leitor há dois elementos que o constituem: a mobilidade informacional associada à mobilidade física do usuário. $\mathrm{A}$ prontidão cognitiva se estabelece na rede, sem barreiras físicas. Nesse momento, também temos a chamada "aprendizagem ubíqua" que se revela enquanto modo de aprender distribuído, dispersivo e assistemático. Sobre isso, Santaella (2013, p. 27) nos diz que:

[...] é muito instável o equilíbrio entre a difusão indiscriminada da informação no ciberespaço e a construção individualizada do conhecimento. $O$ universo das redes é um espaço em constante mutação, dispersivo e assistemático. 0 que ele tem de positivo, a oferta desmedida de informação que pode potencializar a aprendizagem, é contrabalançado, no outro extremo, pela ausência de orientação, cujos efeitos negativos atingem particularmente aprendizes ainda imaturos.

Portanto, a participação na cultura digital, apesar de fundamental, demanda a compreensão de que é preciso considerar a orientação da escola e seu papel formativo nesse contexto. Os alunos participam da cultura digital fora da escola e já participam, consomem e produzem nesses ambientes. No entanto, o que se coloca em pauta é a qualidade científica dessa participação que pode não ser condizente com a formação do leitor e, nesse momento, temos a escola como elemento basilar na constituição de leitores.

Conforme nos diz Pretto (2010), precisamos nos afastar da ideia de uma escola padronizada e baseada na reprodução de saberes. É preciso superar a pedagogia de assimilação e partirmos para processos de "interação e troca entre sujeitos. Interação e troca entre produtos culturais. Recombinagem. Remixagem. Nova produção e diálogo permanente com o instituído, produzindo-se, a partir daí, novos produtos, novas culturas e novos conhecimentos." (PRETTO, 2010, p. 314).

No primeiro parágrafo deste tópico trouxemos as competências na área da Linguagem estabelecidas pela BNCC. Após articular as competências gerais da Educação Básica com as competências específicas da área de Linguagens, a BNCC estabelece competências específicas para o componente curricular de Língua Portuguesa. Elencamos, a seguir, aqueles que se relacionam com a cultura digital e a formação do leitor:

Mobilizar práticas da cultura digital, diferentes linguagens, mídias e ferramentas digitais para expandir as formas de produzir sentidos (nos processos de compreensão e produção), aprender e refletir sobre o mundo e realizar diferentes projetos autorais. (BRASIL, 2018, p. 87).

De acordo com Chartier (2002), a revolução digital permite que o indivíduo realize novas práticas de leitura e escrita tanto inéditas, quanto compartilhadas de forma coletiva, múltipla e 
polifônica, pois "o texto eletrônico, tal qual o conhecemos, é um texto móvel, maleável, aberto. 0 leitor pode intervir em seu próprio conteúdo e não somente nos espaços deixados em branco pela composição tipográfica." (CHARTIER, 2002, p. 25).

Vivenciamos, assim, um movimento de intercâmbio das ideias que dissolve conceitos como estabilidade, singularidade e originalidade da produção textual. Segundo Colomer (2003, p. 68), "é útil pensar a educação literária como uma aprendizagem de percursos e itinerários de tipo e valor muito variáveis. A tarefa da escola é mostrar as portas de acesso. A decisão de atravessá-las e em que medida depende de cada indivíduo".

Há novos suportes para a cultura escrita que incidem diretamente nas práticas de leitura. Nesse sentido, a BNCC parece apontar em direção à autoria e produção de sentidos dentro do componente curricular da Língua Portuguesa.

\section{Considerações Finais}

A reflexão sobre a importância da leitura literária na escola torna-se imprescindível. A literatura tem o poder de reunir e sintetizar diferentes formas de pensamentos, unindo elementos contraditórios e possibilitando as diferenças. A literatura, portanto, como um fenômeno genuinamente humano, ambíguo, relativo, social e dialógico, é essencial na formação do aluno enquanto indivíduo capaz de enxergar o outro, a si mesmo e à sociedade que o engloba.

Nesse contexto, a escola, que submete a criança e o jovem apenas a discursos objetivos e racionais, precisa repensar sobre a importância da presença da subjetividade e das relações humanas dentro de seu espaço educacional. Isso significa que a arte e a literatura precisam estar presentes no aprendizado do aluno, pois possibilitam a pluralidade dos olhares, das verdades, emoções, conflitos e discussões.

A escola, enquanto espaço formativo, enfrenta novos e complexos desafios. A introdução das tecnologias digitais de informação e comunicação acentua tais desafios por desestabilizar paradigmas consolidados sobre o que é ensinar e aprender. 0 aluno que temos hoje representa e significa o mundo a partir de novas perspectivas e, nesse sentido, temos novas necessidades formativas. Assim, é preciso repensar a presença da literatura em sua prática efetiva em sala de aula, desde os anos iniciais até o Ensino Médio, pois as vivências dos alunos que temos hoje perpassam, necessariamente, a mediação tecnológica. As práticas contemporâneas são expressas por novos gêneros e produções textuais com características multissemióticas e multimidiáticas, o que revela a necessidade de 0 aluno compreender estas novas práticas de (multi) letramento (s), assim como seja capaz de ter uma postura ativa e construtiva, se constituindo em leitor e produtor de literatura de forma crítica e artística. 


\section{REFERÊNCIAS}

AZEVEDO, Ricardo. Aspectos instigantes da literatura infantil e juvenil. In: OLIVEIRA, leda de. (org.). 0 que é qualidade em literatura infantil e juvenil? Com a palavra o escritor, São Paulo: DCL, 2005. p. 1-17. Disponivel em: http://www.ricardoazevedo.com.br/wp/wpcontent/uploads/Aspectos-instigantes-da-literatura-infantil-e-juvenil.pdf. Acesso em: 13 fev. 2021.

BRASIL. Ministério da Educação. Base Nacional Comum Curricular. Brasília, 2018. Disponivel em: http://basenacionalcomum.mec.gov.br/images/BNCC_El_EF_110518_versaofinal_site.pdf. Acesso em: 13 fev. 2021.

CANDIDO, Antonio. 0 direito à literatura. In: CANDIDO, Antonio. Vários escritos. 6. ed. Rio de Janeiro: Ouro sobre azul, 2011. p. 171-193.

CHARTIER, Roger. Os desafios da escrita. Tradução: Fulvia Maria Luiza Moretto. São Paulo: Editora da Unesp, 2002.

COLL, Cesar; MONEREO, Charles. Educação e aprendizagem no século XXI: novas ferramentas, novos cenários, novas finalidades. In: COLL, Cesar; MONEREO, Charles. (org.). Psicologia da Educação Virtual: Aprender e Ensinar com as Tecnologias da Informação e da Comunicação. Porto Alegre: Artmed, 2010. p. 15-46.

COLOMER, Teresa. A formação do leitor literário: narrativa infantil e juvenil atual. Tradução: Laura Sandroni. São Paulo: Global, 2003.

CULLER, Jonathan. Teoria literária: uma introdução. Tradução: Sandra Vasconcelos. São Paulo: Beca, 1999.

LAJOLO, Marisa; ZILBERMAN, Regina. Literatura Infantil Brasileira: Histórias e Histórias. 6. ed. São Paulo: Ática, 1985.

LÉVY, Pierre. A inteligência coletiva: por uma antropologia do ciberespaço. 5. ed. São Paulo: Ed. Loyola, 2007

LÉVY, Pierre. 0 que é virtual? São Paulo: Editora 34, 1996.

PRETTO, Nelson. Redes colaborativas, ética hacker e educação. Educ. rev. Belo Horizonte, v. 26, n. 3, p. 305-316, dez. 2010. Disponível em:

https://www.scielo.br/j/edur/a/PCtY6BJVhcXSL6F6wKDpcpq/abstract/?lang=pt. Acesso em: 01 jun. 2021.

SANTAELLA, Lucia. Leitor prossumidor: desafios da ubiquidade para a educação. Ensino Superior Unicamp. Campinas, n. 9, p. 19-28, abr. 2013. Disponível em: https://www.revistaensinosuperior.gr.unicamp.br/edicoes/edicoes/ed09_abril2013/NMES_1.pdf. Acesso em: 01 jun. 2021. 